\title{
Educação Médica no Século XXI: Mudanças no Perfil do Egresso
}

\author{
Medical Training in the 21st Century: \\ Changes in the Graduate Profile
}

Jadete Barbosa Lampert ${ }^{1}$

Em 1920, o Relatório Dawson, de origem inglesa, trouxe como política a regionalização e a distribuição de profissionais com identificação das necessidades de saúde de cada população/região e a integralidade, que fortalece a indissociação entre ações curativas e preventivas. Esse relatório, pouco conhecido em nosso meio acadêmico, se contrapõe ao modelo flexneriano, de 1910, americano, reducionista, biológico, centrado na atenção individual e de cunho curativo, que se difundiu no mundo ocidental e aprofundou a fragmentação do conhecimento. Em movimento contra-hegemônico, a Declaração de Alma-Ata "Saúde para Todos no Ano 2000", de 1978, coloca a Atenção Primária à Saúde (APS) como uma estratégia de organização da atenção à saúde voltada para responder, de forma regionalizada, contínua e sistematizada, à maior parte das necessidades de saúde de uma população, integrando ações preventivas e curativas, bem como a atenção a indivíduos e comunidades.

No movimento de mudanças no perfil do egresso do curso de graduação em Medicina, identifico como brinde neste número da Rbem trabalhos que mostram a relevância da integralidade ao abordarem a saúde na formação dos profissionais, na qual as ciências humanas permeiam estratégias vistas por aspectos variados na proposta de cada estudo.

Assim, aborda as humanidades médicas nas diversas expressões da literatura, focando a interação pessoal. Traz contribuições de Paulo Freire para pensar mudanças de estratégias no ensino de Medicina com inserção na comunidade, na democratização da relação docente-discente e utilização do portfólio com potencial para beneficiar o processo de formação. Um artigo demonstra a importância da compreensão do estudante da abordagem biopsicossocioambiental contida na anamnese e sua contribuição para o cuidado na perspectiva da integralidade. Outro mostra que, na relação paciente-aluno, a maioria dos pacientes aceita de maneira satisfatória participar das aulas práticas e se sente bem em ajudar os futuros médicos.

No contexto do currículo orientado por competência, indicadores podem nortear o processo de planejamento educacional e permitir a participação ativa e a corresponsabilidade dos envolvidos no alcance de uma aprendizagem significativa com vistas a um cuidado qualificado em saúde.

Um artigo relata o modelo de uma escola inovadora que, em ciclos, trata da formação em Saúde no primeiro ciclo como oportunidade de uma escolha vocacional mais madura, aprendizagem para o trabalho em equipe, atualização científica e prática, uso consciente e crítico de tecnologias de cuidado em saúde, com base em valores éticos, políticos e humanísticos.

Dois artigos abordam as possibilidades tecnológicas no uso didático que podem ser potencializadas para aplicação mais ampla na medicina. Modalidades de aprendizagem 
virtual combinadas com métodos convencionais de ensino podem contribuir na educação médica. Esse estudo investigou o perfil de acesso e uso de um portal universitário para atender às demandas informacionais dos graduandos. Relato de experiência da prática de telemedicina em Pediatria de um curso de graduação evidenciou a teleconferência como recurso para consolidar metodologias ativas do processo de ensino-aprendizagem. Desta forma, reforça o protagonismo dos estudantes em sua formação acadêmica como um instrumento importante na integração ensino-serviço e como tecnologia inovadora para a problematização pedagógica de práticas clínicas.

O papel do docente, pedra fundamental do processo de mudança no perfil do egresso, é contemplado em um artigo que aborda o papel dos docentes na formação de novos professores e, ao constatar a importância dos modelos dos mestres, deixa em aberto a necessidade de uma formação específica em docência.

Relevante artigo aborda a Bioética na Estratégia Saúde da Família (ESF), que hoje representa um importante modo de reorientação da APS no Brasil, pautando-se na territorialização e na reorganização das ações de saúde junto às comunidades, salientando a incorporação dos conceitos éticos à ação do profissional, de modo a embasar as decisões autônomas dos membros da equipe.

Destaca-se, ainda, a necessidade de melhoria dos processos associados à pesquisa desde o início da formação, assim como a análise do perfil e da produção científica de pesquisadores para dimensionar o impacto do aumento da produção científica nas áreas de conhecimento. Também, uma tese que trata da (trans)formação da educação médica, constituída por cinco artigos científicos que abordam as transformações contemporâneas da educação médica, questiona e focaliza a possibilidade de mudar o perfil do egresso com base em modificações exclusivas nos métodos de ensino-aprendizagem. Com base na análise, aponta que mudanças pedagógicas isoladas são insuficientes para efetivar a mudança do perfil do egresso, em virtude do complexo processo de formação do médico, que vai além da informação de conteúdos, abrangendo a formação do habitus desta profissão.

Na contextualização histórica do século XX tem-se a dimensão da forma de educar no século XXI - forma que exige dos educadores da medicina esforços de criatividade para não só transmitir, como também construir conhecimentos frente às situações-problema dos mais variados graus de complexidade, para mudanças no perfil do egresso. 